\title{
PROJECT EVALUATION: Validation of a Scale and Analysis of its Predictive Capacity
}

\author{
Rodrigo FERNANDES MALAQUIAS \\ Fernanda Francielle de OLIVEIRA MALAQUIAS \\ Faculdade de Gestão e Negócios, Universidade Federal de Uberlândia, BRAZIL
}

\section{ABSTRACT}

The objective of this study was to validate a scale for assessment of academic projects. As a complement, we examined its predictive ability by comparing the scores of advised/corrected projects based on the model and the final scores awarded to the work by an examining panel (approximately 10 months after the project design).

Results of Confirmatory Factor Analysis (with 161 projects) indicated convergent validity and discriminant validity.

Regression analysis revealed a positive and significant relationship between the scores of projects and final scores of the work, strengthening the claim of the usefulness of the model to minimize potential wear in advising processes.

Keywords: Project evaluation; scale; advising processes.

\section{INTRODUCTION}

\section{Academic Papers:}

A Disagreement about the Advising Process

Advising an academic work consists of a monitoring process whose main objective is to assure that the study carried out by the advisee may have a level of quality consistent with other studies produced and published in their field of research, so as to allow comparability and identify their contribution. There are indications that the advisor has a significant role in this process (see, eg Wygal \& Slout, 1989; Fernandes, Klering \& Aguiar, 1993; Martins, 1997; Freitas, 1998; Freitas, 2002; Leite Filho \& Martins, 2006, Ferreira, Furtado \& Silveira, 2009; Dias, Patrus \& Magalhães, 2011; Mizany, Khabiri \& Sajadi, 2012). Mentoring, voluntarily or forcibly (Martins, 1997), became part of the range of activities developed by teachers. This fact is present especially in stricto sensu postgraduate studies, but this situation has been no different when looking at the scenario of undergraduate courses. 
Thus, there are arguments that not all advisors are or have been adequately prepared to develop an orientation process (Martins, 1997; Flecha, 2003; Leite Filho \& Martins, 2006; Dias, Patrus \& Magalhães, 2011). "Methodology manuals teach what a monograph should be, but do not teach how the teacher should guide the student so he or she may have the internal coherence and articulation required for scientific work" (Dias, Patrus \& Magalhães, 2011, p.715).

Specifically in graduation Course Conclusion Papers (CCP), some students, because they like to read and write or have already accumulated experience with the development of articles in Scientific Initiation projects, for example, may require less from their advisors regarding their orientation skills than those students in the opposite extreme. "Depending on the level of the student's autonomy, that is, his or her experience in research, the role of the advisor will be more or less intense, diverse and frequent (Ferreira, Furtado \& Silveira, 2009, p.171). But this does not indicate that, by itself, the interest and ease of reading and writing of student will ensure a quality academic work, because if the advisor does not have this ability developed, the CCP can be seriously compromised, not being good enough for approval in an examining panel.

It is noteworthy to point one of the basic assumptions that is usually made about advisors: the academic advisor, having gone through a formal orientation process (in which he or she was receiving orientation) and elaboration of a CCP (be it at the Masters or Doctorate level), "would be able to teach research skills" (Leite Filho \& Martins, 2006, p.101). However, as Dias, Patrus \& Magalhães (2011, p.698) point out: "It is not uncommon, among peers, for a masters or doctorate student to refer to his or her advisor as a 'disorientator'. The suffering of the learner in the process of preparing his or her monograph, dissertation or thesis is witnessed by all those present in academia", and this lack of satisfaction also mentioned by Mizany, Khabiri and Sajadi (2012). The fact that the teacher was once an advisee does not necessarily make him or her an apt to advice.

\section{An Alternative to Minimize Tension In The Advising Process}

In response to the contextualized clash, Dias, Patrus and Magalhães (2011, p.701) offered "an alternative orientation of academic papers, through clear parameters on the characteristics that the work to be performed by the student must have". It is a spreadsheet containing items that mainly constitute projects of the Administration area. In the model presented by the authors, these items are grouped in the following major topics:

$>$ for research projects: "Introduction"; "Theoretical Foundation" and "Methodology".

$>$ for the final work: besides the three topics mentioned above, "Analysis and Discussion of Results" and "Conclusions and Suggestions" are included.

In their study, Dias, Patrus and Magalhães (2011) explore in detail each of the topics and their sub-topics, permitting the application of the model more objectively and also allowing potential doubts about its content to be clarified. 
Thus, there is the understanding that, with the application of this model in the analysis of projects and CCPs (whether monographs, dissertations or theses), the absence of parameters in the advising process is minimized, which may contribute to increased advice quality and, consequently, the quality (and quantity) of the advised and defended papers.

Dias, Patrus and Magalhães (2011, p700) show that the model is part of sharing "an experience that is succeeding in the process of academic advising of master's and doctoral level papers". Even with this indication of model fitness, it is understood that a formal analysis of its convergent validity, discriminant validity, internal consistency and reliability, would make the proposal even more robust for application in other studies and practical research activities. The authors stated that: "when submitting an article of this nature, it is hoped that colleagues from the academic community will contribute suggestions, and critical experiments. Other models are possible" (Dias, Patrus \& Magalhães, 2011, p. 715).

\section{Purpose of the Study And Choice Of Research Institution}

The analysis of convergent validity, discriminant validity, reliability and internal consistency of a model is possible by means of statistics applied to it, examples of them being: Exploratory Factor Analysis, Confirmatory Factor Analysis, Cronbach's alpha, the Composite Reliability Index, among other indicators.

With the quantification of each of the items of the model proposed by Dias, Patrus and Magalhães (2011), it is possible to apply this statistic, which is within the scope of this study, and is its overall purpose: to quantitatively validate a scale for the evaluation of academic projects. Considering that the authors' proposed model can be used to evaluate full papers or projects, we also established an additional objective for this study, which is: to analyze the predictive ability of the model by comparing the resulting grades of the advised projects based on the model and the final grades given to the projects by a panel composed of different teachers (which are generally three for graduation and master's and five for doctoral projects).

The implementation of this research, based on the goals set, was possible because of the identification of a federal institution of higher education having in its Accounting course curriculum (semester system), the disciplines of CCP-01, CCP-02 and CCP-03 (Course Conclusion Paper 1, 2 and 3, respectively). It is the School of Accounting Sciences of the Federal University of Uberlândia (FACIC/UFU), which is located in the city of Uberlândia (State of Minas Gerais, Brazil).

This college, that completed 50 years in 2013 and recorded over 2000 graduates in the Accounting course, has 07 administrative staff and 29 effective teachers. In the next 3 years, at least $\mathbf{5 0 \%}$ of its faculty will have a doctoral degree (currently, this percentage is $31.03 \%$ ). In 2013 the institution began offering the Academic Master of Science in Accounting, with 16 regular and 4 special students in this first class. 
In this institution, one teacher per class gives the subject of CCP-01. The purpose of this course is for the student to have, in its conclusion, a research project which will be formally accompanied by a teacher in CCP-02 (for review of the theoretical framework, methodology, data collection and initial analysis of the results) and CCP-03 (for finalization of results analysis, closing statements, reviewing the work and presentation to a panel composed of at least three teachers). Thus, we identified the possibility of applying the model in the CCP-01 course (to examine the convergent validity, discriminant validity, reliability and internal consistency, in statistical terms) and relate its results to grades awarded by a panel approximately $\mathbf{1 0}$ months after the initial analysis and design guidelines (CCP-03). This application is possible because in the subject of CCP-01, the monitoring of the teacher, for advising and evaluating students, is done by means of an instrument whose topics correspond to the model of Dias, Patrus and Magalhães (2011).

In order to facilitate the analysis of what was developed in this study, we drew Figure: 1 below. It also implies a positive relationship between the grades on the evaluation of the project and the grades awarded by the panel in the presentation of the final papers.

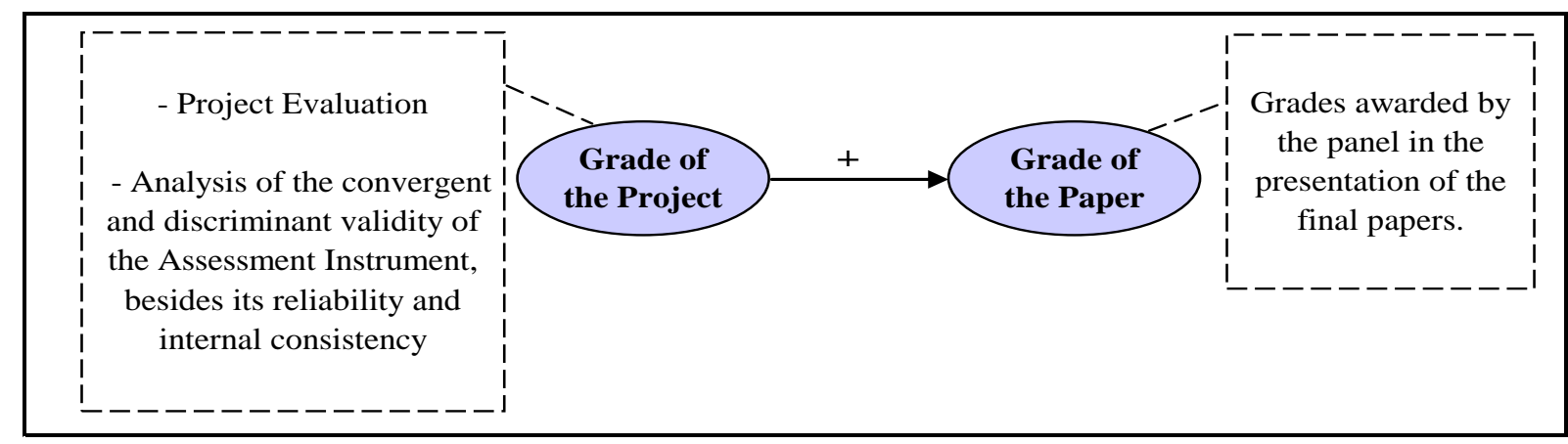

Figure: 1

Diagram illustrating the analysis developed in this study

Notes: CCP-01: Subject of Course Conclusion Paper 01, semestral, taught by one teacher per class, in which the final requirement of the course is the presentation of a research project to continue in CCP-02 and CCP-03. CCP-02: Subject of Course Conclusion Paper 02, semestral, where each student is accompanied by his or her respective advisors, and at the end of the semester a grade is assigned by the advisor. CCP-03: Subject of Course Conclusion Paper 03, semestral, where the student should, with the help of the advisor, complete his or her CCP and present it before a panel of at least three teachers. These subjects are taught at FACIC/UFU.

To achieve the general objective, the following specific objectives were outlined:

$>$ Identify an institution that allows the implementation and monitoring of the model analyzed in an undergraduate, masters or doctoral degree class. As noted above, the institution selected for this study was the FACIC/UFU, undergraduate course; 
$>$ application of the model to the advising of research projects ;

$>$ evaluate the research projects based on the model, assigning grades to each of its items. As stated previously, the teacher responsible for the course of CCP-01 had evaluated (quantitatively) the projects presented in the course with an instrument corresponding to the one of Dias, Patrus and Magalhães (2011). This database created by the teacher was fully available for analysis in this study;

$>$ examine the convergent validity, discriminant validity, reliability and internal consistency of the component topics of the model;

$>$ verify the relationship between the grades assigned to projects in CCP-01 to the grades assigned to the final work by an examining panel in CCP-03.

\section{Topic Relevance and Justification}

"It is urgent to think about the advising and didactic of academia" (Dias, Patrus \& Magalhães, 2011, p. 715) just like "writing" is important in the educational process (Wygal \& Stout, 1989). These statements help understand the importance of further studies on the subject of this work.

A reinforcement can be found in Fernandes, Klering and Aguiar (1993, p. 103), where the authors state that "the difficulties in preparing dissertations and resulting student dropouts as well as the disappointments on the part of mentors deserve an effort to at least begin a discussion of enabling strategies aimed at increasing the rate of production of dissertations", which may also be applicable for course completion papers in general.

According to Freitas (2002, p.93), "when a student does not complete the work, he or she loses what he or she could and would achieve during the credit period... For the institutions involved, everything will be capitalized as losses in their statistics, for the advisor, it will be a personal failure".

We can add to what was already addressed the fact that the area of Teaching and Research in Management and Accounting has received increasing attention from academia in recent years.

The demands in the preparation of academic papers have also grown significantly. A fact that underlies this statement is the amount of unselected papers in the subject area of Education and Research in Accounting at the $13^{\text {th }}$ USP Congress of Controllership and Accounting-2013 (19 abstracts were approved to continue the review process, but only one paper was selected for presentation and discussion at the congress).

Consultation made at the portal of the Ministry of Education (MEC, 2013), in Brazil, there are 1,294 Undergraduate courses in Accounting and 2,686 Undergraduate Administration courses in activity. Given the growth of these courses in recent years, an auxiliary instrument to analyze and monitor the development of CCPs may be an important tool for the teachers to justify their analyses. 
Moreover, a potential stress (Dias, Patrus \& Magalhães, 2011, p. 715) in an advising process can be minimized with the use of a more objective tool to assess/monitor the work, which will optimize the time of the advisor and the advisee.

Thus, it is expected that the results of this study will contribute to the academic community, especially because of the project assessment tool that will be discussed, presented and validated.

We also expected to contribute to future research to be conducted in this field, since, besides the validation proposal, an analysis is being made of a possible determinant of the quality of the final papers presented by students, papers which represent potential articles to be submitted the conferences and journals and subsequently contribute (in one form or another) to the construction of theory (Whetten, 1989) on the subject.

\section{THEORETICAL FRAMEWORK}

The process of developing an academic paper(monographs, dissertations or theses) requires an interaction between the advising teacher and advisee student in all stages, from research, analysis and discussion of the results until its final composition (Ferreira, Furtado \& Silveira, 2009). In the academic environment, Wygal and Stout (1989, p. 246) claim that "writing is a complex process." An important factor in the process of writing a post graduate academic paper is associated with the advisor and the quality of guidance offered (Mizany, Khabiri \& Sajadi, 2012). According to Freitas (2002, p.39), the advisor can be seen as a "regulatory and institutional controller, has his or her name attached to the work and is responsible for what the student does and especially what the student does not do". Therefore, it is expected that the advisor be prepared for the orientation process and deal with the challenges and limitations of the process, which does not always occur (Leite Filho \& Martins, 2006; Dias, Patrus \& Magalhães, 2011).

Ideally, the guidance should be given to qualified teachers with appropriate knowledge and experience and relevant scientific production (Ferreira, Furtado \& Silveira, 2009). At this point, Pinheiro, Melkers and Youties (2012) point out that the publication of the work is a key indicator of research and knowledge production and the co-authoring of the advisor makes all the difference. But what is often perceived is a lack of preparation of both the advisors and the advisees (Fernandes, Klering \& Aguiar, 1993).

Writing an academic paper is not an easy task. This is a complex process that is influenced by several variables, such as the profile and experience of the student and the experience of the advisor (Wigal \& Stout, 1989).

Another factor that can influence the outcome of the work both positively or negatively is the very relationship between the advisor and the advisee. There are many papers dealing with this issue, highlighting it as one of the greatest challenges of the advising process (see, for example: Leite Filho \& Martins, 2006; Viana, 2008; Ferreira, Furtado \& Silveira, 2009; Barth-Teixeira et al., 2011). 
According to Mizany, Khabiri and Sajadi (2012), the advisor is responsible for helping the student in choosing the theme, motivating him or her during the writing of the paper and establishing a good relationship with the student. Thus, the lack of harmony between the advisor and the advisee both in the guidance and on assessment can harm the progress of the work (Freitas \& Zawislak, 1996).

A study by Rodrigues Jr., Fleith and Alves (1993) on the interactions between advisor and advisee based on critical incidents, pointed out that in cases where the orientation process was unsuccessful, the advisors attribute the failure to the advisees.

These, in turn associate the failure to the inability of the advisor to manage the process and the lack of knowledge about the content in addition to non-availability of the advisor. On the subject, Freitas and Zawislak (1996, p.7) argue that one of the factors that negatively affects the orientation process is the "lack of a clear definition of the evaluation criteria, where subjectivity reigns, rather than immediate and objective feedback".

Anyhow, there are many studies that show barriers and challenges related to the advising process as well as the need for better-prepared advisors. Flecha (2003), for example, indicates the importance of providing tools for advisors to perform their role well.

However, there are few works such as the one of Dias, Patrus and Magalhães (2011) aimed at proposing ways to address these barriers and challenges and improve the orientation process. The study conducted by Dias, Patrus and Magalhães (2011), proposed a model that aims to assist advisors in guiding/monitoring the development of academic papers.

By aiming at extending the research originally developed and published by Dias, Patrus and Magalhães (2011) and covering the lack of studies in the area, this study aims to validate a model for the evaluation of academic projects, and to assess its predictive ability.

\section{METHODOLOGICAL ASPECTS}

Data

The accomplishment of the objectives of this work was made possible by contact with an institution of higher education, FACIC/UFU, which features a curriculum structure that allows the completion of the work.

Moreover, there is also the fact that, in developing the subject that involves preparing a project (CCP-01), the teacher uses an instrument corresponding to the model presented by Dias, Patrus and Magalhães (2011). Frame 1, below, shows a comparison between the instrument used by the CCP-01 teacher and model of the mentioned authors. 


\begin{tabular}{|c|c|c|}
\hline $\begin{array}{l}\text { General } \\
\text { Topics }\end{array}$ & $\begin{array}{c}\text { Model proposed by } \\
\text { Dias, Patrus e Magalhães (2011) } \\
\text { (for projects) }\end{array}$ & Model used in CCP-01 (for projects) \\
\hline \multirow{6}{*}{ Introduction } & Contextualization & Contextualization \\
\hline & Research Question & Research Problem \\
\hline & General purpose & General purpose \\
\hline & Specific Objectives & Specific Objectives \\
\hline & Practical justifications & Justifications and Relevance of Topic \\
\hline & Theoretical justifications & - \\
\hline \multirow{2}{*}{$\begin{array}{l}\text { Theoretical } \\
\text { grounding }\end{array}$} & Literature Review & Theoretical - Definitions and concepts \\
\hline & Guiding issues and/or Hypotheses & Theoretical - Previous Studies \\
\hline \multirow{7}{*}{ Methodology } & Research Design & Research classification - Approach \\
\hline & Population and Sample & Research classification - Procedures \\
\hline & Variable Instrumentation & - \\
\hline & Data Collection - Instrument & Method of Data Collection \\
\hline & Data Collection - Process & - \\
\hline & Methods of Analysis & Method of Data Analysis \\
\hline & Boundaries and Limitations & Limitations of the Study \\
\hline \multirow{4}{*}{$\begin{array}{l}- \\
- \\
- \\
-\end{array}$} & References & References - According to ABNT \\
\hline & Appendices and Annexes & Timetable \\
\hline & - & General Structure of the Project \\
\hline & - & Citations in General - According to ABNT \\
\hline
\end{tabular}

Frame: 1

\section{Comparison of assessment instruments addressed in this study}

Source: first and second columns: adapted from Dias, Patrus and Magalhães (2011), third column: adapted from a worksheet courtesy of a FACIC/UFU CCP-01 teacher.

As Frame: 1 shows, the content of the assessment instruments are similar, since they assess the research project based on three main areas: Introduction, Theoretical Framework and Methodology, besides formal aspects. The big difference between the models lies in the fact that the instrument used by CCP-01 teacher considers a scale of 0 to $\mathbf{1 0}$ for each item evaluated. Ie, if the Context of the Study fails to comply with its purpose, it scores zero. If it caters adequately, is well written and the ideas are well concatenated, it scores 10 . If there is concatenation of ideas, but this contextualization does not take to the research question, the score is average, and so on, varying according to each case (the scores can also be fractioned, for example, 9.5). 
According to the teacher of the course, this spreadsheet is shown to the students in two stages: first, after the presentation of initial discussions about the project, students deliver the first version to the teacher, whom, using the worksheet, assigns a score to each of the items for each student (this version is worth the equivalent of $5 \%$ of the semester grade). Based on the spreadsheet scores, students have a parameter to correct their project and consult the teacher. After about two weeks, students deliver the final version, which is again evaluated based on the spreadsheet and the score is released to students by registration number, which is the second stage of the disclosure of the spreadsheet. The score of this second version corresponds to $40 \%$ of the semester course grade, which is calculated proportionally based on the arithmetic average of the scores of its items.

\section{Data Collection Was Performed In the Following Sources \\ CCP-01 Project Grades}

Project grades resulting from the application of the assessment instrument used by the teacher as well as grades concerning each of the items of the assessment instrument were provided by the subject teacher for the period 5 semesters (this grade corresponds to the final version of the project). The period was not longer because this new curriculum framework, involving the preparation of a CCP by students, came into effect at FACIC/UFU in 2007. Consequently, the first classes of the new curriculum began to attend CCP in 2010, since this course is offered in the 8th Period (CCP-01, 8th period, CCP-02, 9th Period; CCP-03, 10th Period). It is worth mentioning that CCP-01 is a prerequisite for CCP-02, and CCP-02 is a prerequisite for CCP-03. Besides it, as a prerequisite to take the CCP-01 course, students must have attended and have been approved in all subjects up to the 6th period. Number of valid observations: 161 (2010/02, 2011/01, 2011/02, 2012/01, and 2012/02).

\section{CCP-03 Grades}

These were obtained from the Coordination of Undergraduate Accounting Sciences Office FACIC/UFU. In a public presentation, an examining panel, composed of at least three teachers, as already explained, awards this grade. Number of valid observations: 79 $(2011 / 02,2012 / 01$, and 2012/02). That is, until 2013/01, only three classes had attended CCP-03 and at the time of the beginning of data collection, information relating to 2013/01 was not available. Quantitative analysis was divided into two major steps, which are explained below:

$>$ validation of the questionnaire, and

$>$ analysis of the relationship between the grades of the CCP-01 projects with the CCP-03 grades.

Validation of Questionnaire and Regression Analysis

In the quantitative evaluation stage of the questionnaire, we initially applied the Exploratory Factor Analysis (EFA), with the objective of determining whether the grouping of variables would be similar to those proposed by Dias, Patrus and Magalhães (2011). 
In other words, the objective of this analysis was to evaluate if the components of the Introduction would be grouped in the same factor, if the components of the methodology would be grouped in another factor, and so on.

The method used was Principal Component Analysis with Varimax rotation, accompanied by KMO (Kaiser-Meyer-Olkin) and Bartlett Sphericity tests, showing the fitness of data to the AFE. As a criterion for the number of factors to be extracted, we used the "Latent Root Criterion", extracting factors with eigenvalues greater than 1 (Hair et al., 2005, p.101).

On the sample size, Hair et al. (2005, p.98) point out that "as a general rule, the minimum is to have at least five times more observations than the number of variables to be analyzed, and the more acceptable size would have a ratio of ten to one. Some researchers even propose a minimum of $\mathbf{2 0}$ cases for each variable".

The instrument being evaluated contains 16 questions, which indicates a need for at least 80 respondents and maximum of $160(16 \times 5=80$ and $16 \times 10=160)$. With this, the number of observations from CCP-01 (161, as explained previously) is in the upper limit of this ratio.

As we already have a theoretical model that underlies the organization of the evaluation instrument, more robust procedures for analysis of convergent validity and discriminant validity of the instrument were applied. As explained by Kline (2011, p. 71-72),

\section{A set of variables presumed to measure the same construct shows convergent validity if their intercorrelations are at least moderate in magnitude. In contrast, a set of variables presumed to measure different constructs shows discriminant validity if their intercorrelations are not too high.}

Thus, with regard to convergent validity, Cronbach's Alpha and the Reliability Composite Index were calculated for each construct. For these two indicators, we expected to obtain values of at least 0.70 (Hair et al., 2005).

However, Hair et al. (2005) also emphasize that in exploratory research, a minimum of 0.60 for these two indicators is accepted. For the discriminant analysis, noting the study of Paiva, Roth and Fensterseifer (2008) as well as the recommendations of Kline (2011), we checked the chi-square statistic differences between pairs of factors (Introduction $x$ Theoretical Framework, for example) perfectly correlated and the factors evaluated with free correlation.

This procedure was repeated for the three possible combinations of factors: Introduction $x$ Theoretical Framework; Introduction $x$ Methodology; Theoretical Framework $x$ Methodology. 
The objective of this procedure is to, for example, examine whether the items used to assess the Introduction of the project are measuring aspects related to the introduction or if aspects of methodology are also present.

Greater consistency would be found if grades for the items of methodology were part of the methodology group, not mixed with Introduction and Theoretical Framework. There may be a positive correlation between these factors, but they are not necessarily part of the same factor. The perfect correlation between different factors indicates specification problems.

This step is part of the procedures for the Confirmatory Factor Analysis (CFA), which is "particularly useful in the validation of scales for the measurement of specific constructs" (Hair et al., 2005, p.493).

For the CFA, the following indicators were observed, based on considerations of Byrne (2001) and Hair et al. (2005):

$>$ Chi-square statistic, which is expected to be not significant for the differences in anticipated and actual matrices. However, this statistical analysis must be done in conjunction with the others, as it is sensitive to sample size.

$>$ Comparative indexes: normed fix index (NFI), comparative fit index (CFI), incremental fit index (IFI) and Tucker-Lewis index (TLI), where values above 0.90 indicate optimal fitness.

> Absolute measure adjustment: Indicators goodness-of-fit index (GFI). Recommended values are close to $\mathbf{0 . 9 0}$.

$>$ Root mean square error of approximation (RMSEA) statistic, with a recommended value below $5 \%$ in well-fit models, or below $8 \%$ for cautious analyses.

Finally, to analyze the relationship between the study variables, the linear regression analysis by the method of Ordinary Least Squares (Hair et al., 2005, p.493) was applied, and their standardized residuals were analyzed for normality through the KolmogorovSmirnov test.

\section{RESULTS}

\section{Questionnaire Validation}

The first step consisted of the descriptive analysis of the issues that make up the research model. The results are displayed in Table: 1 here. Table: 1 show that, on average, students receive good reviews in the final version of theirCCP-01 project because the average score for most items evaluated is above seven, and many of them, near or exceeding eight. Even 
Table: 1

Descriptive statistic of variables in the evaluation instrument

\begin{tabular}{|c|c|c|c|c|c|c|}
\hline Factor & Variable/Model item & $\mathbf{n}$ & Avg. & Std. Dev. & Min. & Max. \\
\hline \multirow{5}{*}{ Introd. } & Contextualization & 161 & 7.976 & 2.359 & 0.000 & 10.000 \\
\hline & Research Problem & 161 & 8.665 & 2.691 & 0.000 & 10.000 \\
\hline & General purpose & 161 & 8.932 & 2.056 & 0.000 & 10.000 \\
\hline & Specific Objectives & 161 & 7.932 & 3.224 & 0.000 & 10.000 \\
\hline & Justifications and Relevance of Topic & 161 & 7.982 & 2.554 & 0.000 & 10.000 \\
\hline \multirow{2}{*}{$\begin{array}{l}\text { Theoretical } \\
\text { grounding }\end{array}$} & Theoretical - Definitions and concepts & 161 & 7.802 & 2.434 & 0.000 & 10.000 \\
\hline & Theoretical - Previous Studies & 161 & 6.640 & 3.562 & 0.000 & 10.000 \\
\hline \multirow{5}{*}{ Method. } & Research classification - Approach & 161 & 8.087 & 2.604 & 0.000 & 10.000 \\
\hline & Research classification - Procedures & 161 & 7.783 & 2.92 & 0.000 & 10.000 \\
\hline & Method of Data Collection & 161 & 7.087 & 3.314 & 0.000 & 10.000 \\
\hline & Method of Data Analysis & 161 & 5.796 & 3.777 & 0.000 & 10.000 \\
\hline & Limitations of the Study & 161 & 6.280 & 4.067 & 0.000 & 10.000 \\
\hline \multirow{4}{*}{ Form } & References - According to ABNT & 161 & 7.249 & 3.279 & 0.000 & 10.000 \\
\hline & Timetable & 161 & 9.143 & 2.159 & 0.000 & 10.000 \\
\hline & General Structure of the Project & 161 & 8.056 & 2.368 & 0.000 & 10.000 \\
\hline & Citations in General - According to ABN & 161 & 6.957 & 3.331 & 0.000 & 10.000 \\
\hline
\end{tabular}

Notes: each item of the model was evaluated based on a score of 0 to 10.

The Factor 'Form' was included in this spreadsheet as a way to identify the last four items.

so, there are students who scored zero in some of the items, as well as students who scored a 10. With this database, we proceeded to the EFA and the results are reported in Table 2, for the rotated matrix. 
There was a lot of consistency in the loads displayed by the factors, with the correspondence available in Frame: 2 being suggested in this paper.

Table: 2

Results for Exploratory Factor Analysis (EFA)

\begin{tabular}{llccc}
\hline Factor & Variable/Model item & Factor 01 & Factor 02 & Factor 03 \\
\hline \multirow{4}{*}{ Introd. } & Contextualization & 0.598 & 0.494 & --- \\
& Research Problem & --- & 0.715 & --- \\
& General purpose & --- & 0.764 & --- \\
& Specific Objectives & --- & 0.665 & --- \\
\hline \multirow{2}{*}{ Theoretical } & Justifications and Relevance of Topic & --- & 0.575 & --- \\
\hline \multirow{5}{*}{ Trounding } & Theoretical - Definitions and concepts & 0.492 & --- & 0.531 \\
& Theoretical - Previous Studies & --- & --- & 0.636 \\
\hline \multirow{3}{*}{ Method. } & Research classification - Approach & 0.834 & --- & --- \\
& Research classification - Procedures & 0.842 & --- & --- \\
& Method of Data Collection & 0.839 & --- & --- \\
& Method of Data Analysis & 0.664 & --- & --- \\
& Limitations of the Study & --- & 0.623 & --- \\
\hline \multirow{5}{*}{ Form } & References - According to ABNT & --- & --- & 0.627 \\
& Timetable & --- & --- & 0.793 \\
& General Structure of the Project & 0.56 & --- & 0.502 \\
& Citations in General - According to ABNT & 0.518 & --- & 0.495 \\
\hline
\end{tabular}

Notes: "---" refers to loads lower than 0.45 , which were excluded for best viewing of the results.

The results presented in Table: 2 suggest the creation of three factors (remembering that the criterion used to determine the number of factors was the "Latent Root Criterion", in which the factors with eigenvalues greater than 1were extracted).

\begin{tabular}{|ll|}
\hline Factors & Correspondence \\
\hline Factor 01 & $\begin{array}{l}\text { Aspects related to the methodology of the study, its overall structure and } \\
\text { obedience to the rules of ABNT (formatting). }\end{array}$ \\
\hline Factor 02 & Aspects of the introduction of the study and its limitations. \\
\hline Factor 03 & Aspects related to Theoretical Framework, References and timetable \\
\hline
\end{tabular}

Frame: 2

Identification of factors created by EFA 
The three factors identified shown themselves compliant to the proposal of Dias, Patrus and Magalhães (2011), which already shows an exploratory result regarding the instrument evaluated. However, since these results are based on the EFA, there is only slight evidence that this compliance is adequately measured. To measure this compliance with a more robust statistic was applied to the CFA.

For the application of CFA, it was necessary to establish the test model and link each item to its respective factor. Figure 2 describes the bindings performed, based on the original model being tested and also based on the results of EFA for allocation of variables in the factor "Form".

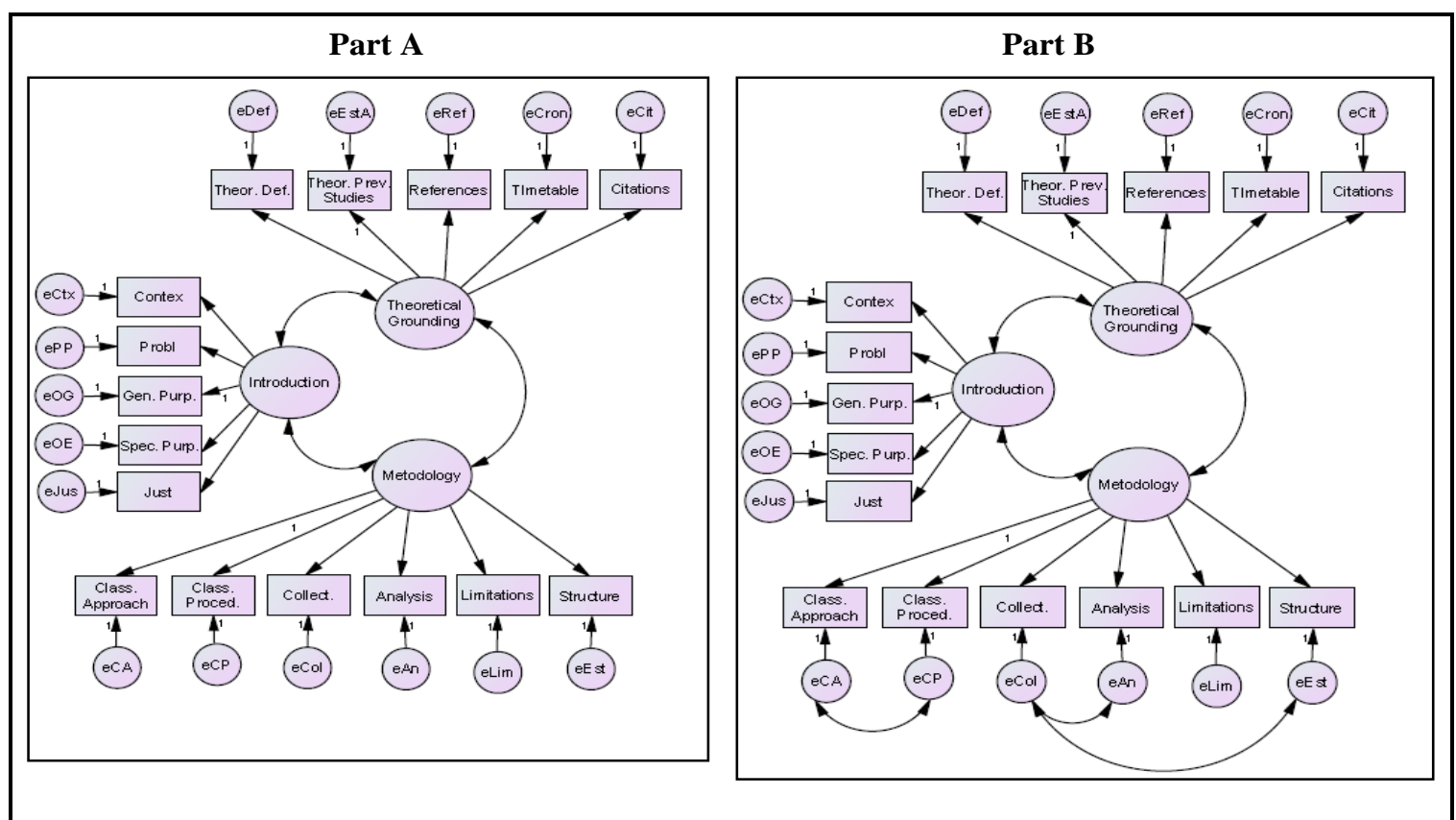

Figure: 2

Model used for the Confirmatory Factor Analysis (CFA)

Notes: Indicators for the Model relative to Part B of the Figure: Chi-Squared Statistics: 178.639 with 98 degrees of freedom. Chi-Square weighted by the degrees of freedom: 1,823. NFI: 0.892. CFI: 0.947. IIF: 0,948. TLI:

0.935. GFI: 0.880. RMSEA: 7.17\%. RMSEA LO 90: 5.48\%. HI RMSEA 90: 8.82\%.

Part A of Figure: 2 refer to the first version of the model. After analyzing the adjustment indicators of Part $A$, observed in conjunction with the modification indexes, three correlations were added between the error terms of the Research Classification:

$>$ Method of Approach with Procedure Method

$>$ Method of Collection with form of data analysis, and,

$>$ Method of Collecting data with General Structure of Paper 
The new model

With the inclusion of these correlations, model fitting (available in Part B of Figure 2) was satisfactory, being:

$>$ Chi-Squared Statistics: despite being significant at $5 \%$ level, its value divided by the degrees of freedom $(178.639 / 98=1.823)$ was less than 3 (Kline, 2011), indicating a reasonable fit, which should be assessed in conjunction with other indicators.

$>$ Comparative indexes indicated optimal fittings, obtaining the following: NFI (0.892), CFI (0.947), IFI (0.948) and TLI (0.935).

$>$ Absolute fitness measure: GFI $(0.880)$ was close to 0.90 , as indicated by literature.

$>$ The (RMSEA) statistic was $7.17 \%$, and its confidence interval was as follows: $5.48 \%$ (90 LO) and $8.82 \%$ (HI 90). Thus, its lower limit was close to the minimum recommended, and its average value was below $8 \%$.

Then we calculated Cronbach's Alpha and the Reliability Composite Index, to verify the reliability and internal consistency of each factor of the model analyzed.

The results are summarized in Table: 3 and indicate appropriate fitness, since the literature recommends levels of at least $\mathbf{0 . 7 0}$ (all measurements presented were above the minimum recommended).

Table: 3

Cronbach's Alpha and the Composite Reliability Index of the model analyzed

\begin{tabular}{lccc}
\hline Factors & $\begin{array}{c}\text { No. of } \\
\text { items }\end{array}$ & $\begin{array}{c}\text { Cronbach's } \\
\text { Alfa }\end{array}$ & $\begin{array}{c}\text { Composite Reliability } \\
\text { Index }\end{array}$ \\
\hline Introduction & 5 & 0.798 & 0.976 \\
Theoretical Grounding & 5 & 0.779 & 0.962 \\
Methodology & 6 & 0.871 & 0.981 \\
\hline
\end{tabular}

As can be seen in Part B of Figure: 2, was inserted a correlation between the three factors of evaluation of projects.

To check the level of specification of the model, ie, to verify whether the factors are measuring different aspects of the projects of each student, the discriminant validity was performed and results are available in Table: 3.

Available statistics refer to reviews by pairs of factors. 
Table: 3

Results for the discriminant validity

\begin{tabular}{|c|c|c|c|c|c|c|}
\hline \multirow{2}{*}{ Pairs of Factos } & \multicolumn{2}{|c|}{ No Restrictions } & \multicolumn{2}{|c|}{$\begin{array}{l}\text { With Perfect } \\
\text { Correlation }\end{array}$} & \multicolumn{2}{|c|}{ Chi-Square Difference } \\
\hline & $\begin{array}{l}\text { Chi- } \\
\text { Square }\end{array}$ & d.f. & $\begin{array}{l}\text { Chi- } \\
\text { Square }\end{array}$ & d.f. & Difference & Significance \\
\hline \multicolumn{7}{|l|}{ Introduction } \\
\hline Theoretical Groundin & 54.383 & 34 & 75.854 & 35 & 21.471 & $<0.01$ \\
\hline Methodology & 83.121 & 40 & 135.376 & 41 & 52.255 & $<0.01$ \\
\hline \multicolumn{7}{|l|}{ Theoretical Grounding } \\
\hline Metholodogy & 92.751 & 40 & 131.468 & 41 & 38.717 & $<0.01$ \\
\hline
\end{tabular}

Note: read the value of $\mathbf{2 1 . 4 7 1}$ as follows: the pair of factors Introduction and Theoretical Framework with free correlation between them, showed a chi-square statistic of 54.383 with 34 degrees of freedom. This same pair of factors with the correlation between them fixed at one presented a chi-square statistic of $\mathbf{7 5 . 8 5 4}$ with 35 degrees of freedom. The difference between the chi-square statistics was 21.471 (75.854 to 54.383) that with one degree of freedom is statistically significant at $1 \%$.

Although we included correlations between the factors "Introduction", "Methodology" and "Theoretical Framework" in the model in Figure 2, the discriminant analysis indicated that they measure different aspects within the assessment tool. Ie, they are not confused when assessed together and have behaviors with similar variations in assessments of projects of different students.

These results are favorable to the fitness of the instrument for measuring aspects related to different factors of the research projects.

\section{Analysis of the Relationship Between}

The Grades of Projects and the Final Grades of the Work

Having validated the assessment tool used by the CCP-01 teacher, the following procedure consisted in the linear regression analysis between the grades of projects and the final work grades in CCP-03.

For the final grade of the project, an arithmetic average obtained from 16 evaluation items was considered. Table 4 shows the descriptive statistics of the two variables. 
Table: 4

Descriptive statistics for the grades of projects and final grades of papers

\begin{tabular}{lccccc}
\hline Variables & n & Avg. & Std. Dev. & Min. & Max \\
\hline Project Grade & 79 & 7.165 & 2.198 & 0.000 & 10.000 \\
CCP-03 Grade & 79 & 85.468 & 9.670 & 40.000 & 98.000 \\
\hline \multicolumn{5}{c}{ Note: The project grade varies on a scale of 0 to 10; } \\
the CCP-03 grade varies on a scale of 0 to 100.
\end{tabular}

As Table: 4 shows, there were students who scored zero on the project, as there were students who scored ten. As for the final grade of the work, the minimum grade awarded was 40 points and the maximum 98 points. Ie, there is still no record of a score of 100 by a panel of examiners in the analysis of CCPs, with an average score equal to 85.468. The result of the linear regression analysis is available in Table: 5.

Table: 5

Results for the linear regression analysis

\begin{tabular}{lcccc}
\hline Variables & Beta & Std. Error & T Statistic & Sig. \\
\hline Constant & 69.218 & 4.126 & 16.774 & 0.000 \\
Project Grade & 2.175 & 0.536 & 4.058 & 0.000 \\
\hline N & 79 & -- & -- & -- \\
R2 adjusted & 0.165 & -- & -- & -- \\
Sig.(Residuals) & 0.211 & -- & -- & -- \\
Sig.(F-Test) & 0.000 & -- & -- & -- \\
\hline
\end{tabular}

Notes: Sig. (Residuals): significance for the Kolmogorov-Smirnov test applied to the standard residues in the linear regression analysis. Sig. (F-Test): significance for the $F$ test of the regression model.

The results of the regression analysis assist in the test of the positive sign shown in Figure 1, in the introduction of this study. I.e., the beta on the grade of the project had a positive (2.175) and significant value at $1 \%$ level. This indicates that, on average, an increase of one grade unit in the project provides an increase of 2.175 CCP-03 grade units.

The observed relationship between the grade of the project and the final grade of the work indicate that there is a positive and significant relation to the assessment conducted based on the instrument used by the teacher and the grade given by a panel composed of three different teachers. The test of normality of residuals indicates good fits for the regression analysis performed. 
The results also underlie the reasoning that, on average, students with lower grades on projects also have a tendency to achieve lower grade on CCP- 03 (almost 10 months after the project evaluation).

The main finding to be highlighted is the following: the instrument used in CCP-01 to advise/monitor research projects, which is consistent with that proposed by Dias, Patrus and Magalhães (2011), has reliability, internal consistency, enables the measurement of different aspects of research projects, and the evaluation as a result of its application has significant positive relationship with the grades of the final works later presented before an examining panel.

\section{FINAL CONSIDERATIONS}

The advising process, although essential to the smooth running of academic activities, does not always culminate with the expected results for the parties involved (advisor and advisee).

In order to reduce the consequences of the lack of standards in the guidance processes, Dias, Patrus and Magalhães (2011) proposed a model that helps to advise/monitor the development of academic papers. An equivalent instrument to that proposed by these authors was already being used to evaluate projects in the discipline of CCP-01 at FACIC/UFU, this instrument being subjected to quantitative treatments in this study.

The results showed that the instrument reported adequate levels of reliability and internal consistency (in statistical terms), and allowed the measurement of different aspects contained in research projects, which was confirmed by the analysis of convergent and discriminant validity of the model.

Moreover, the results showed strong evidence that the project grades resulting from the application of the assessment tool had a positive and statistically significant relationship with the grades obtained in CCP-03 of the final works defended by the students.

That is, on average, students who received good reviews in the project also received good reviews from the examiners at the time of their public presentation.

That conclusion was possible because, in $\mathrm{CCP}-03$, the final work was assessed based on the average grade of the examining panel, ranging from 0 to 100 . If, inCCP-03, the criterion had been: approved or failed, without a grade representing a scalar measure, the analyses developed between the grades of the project and the final evaluation of the work would not be possible.

This is a limiting factor for the application of this relationship (project grades with dissertation/thesis presentation grades) in Stricto-Sensu post-graduation, but this does not preclude the use of a validated instrument to advise/monitor the development of research projects in these courses. 
The results allow us to extend the research originally developed and published by Dias, Patrus and Magalhães (2011), also giving it more robustness. Its relevance is obvious to minimize potential stress in the advising processes, especially in undergraduate courses, environment in which the results were tested.

The quality of guidance and the work produced by the students are the first steps to developments in advanced studies and publications that may allow high theoretical and methodological rigor which is essential for building theory (Whetten, 1989) in any area of knowledge. Three limiting factors are linked to the results of this study:

$>$ the number of observations available for analysis, because only the projects of five different classes were considered in the study,

$>$ the 161 projects were evaluated by only one teacher.

However, the result obtained, revealing significant positive relationship between the grades given by the teacher and the grades awarded by different panels, indicates that the assessment is in line with the perceptions of different evaluators, and the study was conducted with a database from only one institution.

Thus, further studies are recommended and new applications of the model in other higher education institutions. For future research, we suggest a (quantitative) application of the model in Stricto-Sensu graduate course projects, observing whether its reliability, internal consistency, convergent and discriminant validity will be maintained, as observed in this study.

We also suggest the inclusion of additional explanatory variables in the linear regression analysis performed in order to increase the variability explained by the equation.

\section{BIODATA AND CONTACT ADDRESSES OF THE AUTHORS}

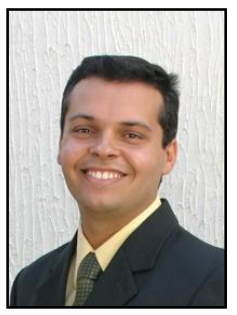

Rodrigo FERNANDES MALAQUIAS is graduated in accounting, has master degree and PhD in business administration. He is currently professor of accounting (Federal University of Uberlandia).

Rodrigo FERNANDES MALAQUIAS

Faculdade de Ciências Contábeis, Universidade Federal de Uberlândia, BRAZIL

Av. João Naves de Ávila, no 2121, Bloco F, Sala 1F-215.

Bairro: Santa Mônica. CEP: 38.400-902. Uberlândia, MG, BRAZIL

Phone/fax: (+55) (34) 3239-4176

Email: rodrigofmalaquias@yahoo.com.br 


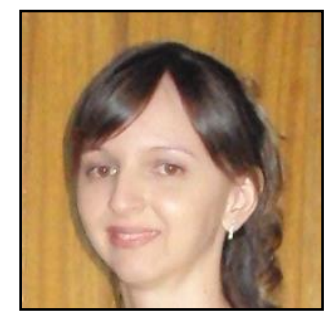

Fernanda Francielle de OLIVEIRA MALAQUIAS is graduated in computer science has master degree in computer science and has PhD in electrical engineering. She is currently professor of management (Federal University of Uberlandia).

Fernanda Francielle de OLIVEIRA MALAQUIAS

Faculdade de Ciências Contábeis, Universidade Federal de Uberlândia, BRAZIL

Av. João Naves de Ávila, no 2121, Bloco F, Sala 1F-215.

Bairro: Santa Mônica. CEP: 38.400-902. Uberlândia, MG, BRAZIL

Phone/fax: (+55) (34) 3239-4176

Email: fernandafrancielle@yahoo.com.br

\section{REFERENCES}

Barth-Teixeira, E., Froemming, L. M. S., Drews, G. A., \& Zamberland, L. (2011). Relação OrientadorOrientando e seus Reflexos na Elaboração do Trabalho de Conclusão de Curso (CCP): uma avaliação no curso de administração da UNIJUÍ [The Relationship between Advisor and Orienting and its Reflections in Preparation for Course Conclusion Papers (CCP): an evaluation in the course of administration of UNIJUÍ], Anais do Colóquio Internacional Sobre Gestão Universitária na América do Sul, Florianópolis, Brasil, XI.

Byrne, B. M. (2001). Structural Equation Modeling with AMOS: basic concepts, applications, and programming. Mahwah, New Jersey: Lawrence Erlbaum Associates.

Dias, S. M. R., Patrus, R., \& Magalhães, Y. T. (2011). Quem ensina um professor a ser orientador? Proposta de um modelo de orientação de monografias, dissertações e teses [Who Teaches a Teacher to be na Advisor? Proposing a Model of Guidance for Monographs, Dissertations and Theses]. Administração: Ensino e Pesquisa, 12(4), 697-721.

Fernandes, E. C., Klering, L. R., \& Aguiar, D. Q. (1993). Dissertação de Mestrado: elementos inibidores e facilitadores [Master's Dissertation: Elements inhibitors and facilitators]. Revista de Administração, 28(2), 103-116.

Ferreira, L. M., Furtado, F., \& Silveira, T. S. (2009). Relação Orientador-Orientando: o conhecimento multiplicador [The Advisor-Orienting Relationship: the multiplier knowledge]. Acta Cirúrgica Brasileira, 24(3).

Flecha, B. S. C. (2003). Mestrandos à Deriva: cadê o orientador? [Master's in Drift: where's advisor?] Assembléia Legislativa do Estado de Minas Gerais. Banco de Conhecimento - Estudos Temáticos. 
Freitas, H. M. R., \& Zawislak, P. A. (1996). Como deve ser, afinal, o desenvolvimento do processo de mestrado em administração? [How it should be, after all, the development of the master's process in the management area?], REAd-Revista Eletrônica de Administração, 2(1).

Freitas, M. E. (2002). Viver a tese é preciso! Reflexões sobre as aventuras e desventuras da vida acadêmica [Living the thesis is necessary! Reflections on the adventures and misadventures of academic life]. RAE-Revista de Administração de Empresas, 42(1), 88-93.

Freitas, M. H. A. (1998). Avaliação da produção científica: considerações sobre alguns critérios [Evaluation of scientific production: considerations on some criteria]. Psicologia Escolar e Educacional, 2(3), 211-228.

Hair, J. F., Anderson, R. E., Tatham, R. L. \& Black, W. C. (2005). Multivariate Data Analysis. 5.ed. Bookman.

Kline, R. B. (2011). Principles and practice of structural equation modeling. 3.ed. London: Guilford Press.

Leite Filho, G. A., \& Martins, G. A. (2006). Relação Orientador-Orientando e Suas Influências na Elaboração de Teses e Dissertações [The Relationship Between Academic Advisors and Graduate Students and Their Influences in the Process Leading of Research to the Completion of Thesis and Dissertations]. RAE-Revista de Administração de Empresas, 46.

Martins, G. A. (1997). A relação orientador $x$ orientando na elaboração de trabalhos técnico científicos [The Relationship Between Academic Advisors and Orienting in the Preparation of Scientific and Tecnical Papers]. Anais dos Seminários em Administração da USP, São Paulo, Brasil, II.

MEC - Ministério da Educação. (2013). E-MEC [Electronic Consultation - Brazilian Ministry of Education]. Instituições de Ensino Superior e Cursos Cadastrados / Consulta Avançada. Retrieved July 21, 2013, from: http://emec.mec.gov.br

Mizany, M., Khabiri, M. \& Sajadi, S. N. (2012). A study of the capabilities of graduate students in writing thesis and the advising quality of faculty members to pursue the thesis. Procedia-Social and Behavioral Sciences, 31, 5-9.

Pinheiro, D., Melkers, J., \& Youtie, J. (2012). Learning to play the game: student publishing as an indicator of future scholarly success. Technological Forecasting \& Social Change.

Rodrigues Jr., J. F., Fleith, D. S. \& Alves, K. M. B. (1993). A Dissertação de Mestrado: um estudo sobre as interações entre o orientador e o orientando com base em incidentes críticos [The Master's Dissertation: a study of the interactions between the academic advisor and the orienting based on critical incidents]. Revista Brasileira de Estudos em Psicologia, 74(177), 437-463. 
Viana, C. M. Q. Q. (2008). A Relação Orientador-Orientando na Pós-Graduação Stricto Sensu [The Advisor-Orienting Relationship in the Post-Graduate]. Linhas Críticas, 14(26), 93-109.

Whetten, D. A. (1989). What Constitutes a Theoretical Contribution?, Academy of Management Review, 14(4), 490-495.

Wigal, D. E. \& Stout, D. E. (1989). Incorporating Writing Techniques in The Accounting Classroom: experience in financial, managerial and cost courses. Journal of Accounting Education, 17, 245-252. 